08

\title{
Анализ структурной эволюции порошков оксида цинка, полученных методом механического высокоэнергетического размола
}

\author{
(C) И.А. Аверин, ${ }^{1}$ И.А. Пронин, ${ }^{1,2,9}$ Н.Д. Якушова, ${ }^{1}$ А.А. Карманов, ${ }^{1}$ М.М. Сычев, ${ }^{3,4}$ С.В. Вихман, ${ }^{3}$ \\ B.С. Левицкий, ${ }^{5}$ В.А. Мошников, ${ }^{1,2}$ Е.И. Теруков ${ }^{6}$ \\ ${ }^{1}$ Пензенский государственный университет, \\ 440026 Пенза, Россия \\ ${ }^{2}$ Санкт-Петербургский государственный электротехнический университет „ЛЭТИ“ им. В.И. Ульянова (Ленина), \\ 197022 Санкт-Петербург, Россия \\ ${ }^{3}$ Санкт-Петербургский государственный технологический институт (технический университет), \\ 190013 Санкт-Петербург, Россия \\ ${ }^{4}$ Институт химии силикатов им. И.В. Гребенщикова РАН, \\ 199034 Санкт-Петербург, Россия \\ ${ }^{5}$ ООО НТЦ ТПТ, \\ 194064 Санкт-Петербург, Россия \\ ${ }^{6}$ Физико-технический институт им. А.Ф. Иоффре РАН, \\ 19402 Санкт-Петербург, Россия \\ ฯ e-mail: pronin_i90@mail.ru
}

Поступило в Редакцию 22 декабря 2018 г.

В окончательной редакции 22 декабря 2018 г.

Принято к публикации 25 марта 2019 г.

С использованием методов сканирующей электронной микроскопии, тепловой десорбции азота, спектроскопии комбинационного рассеяния инфракрасной фурье-спектроскопии исследованы порошки оксида цинка, изготовленные методом механического высокоэнергетического размола. Продемонстрирована их структурная эволюция, включающая уменьшение среднего размера кристаллитов, увеличение удельной площади поверхности, а также изменение числа и соотношения адсорбционных центров. Представлены данные о реконструкции поверхности порошков оксида цинка и множественных разрывах связей в приповерхностных областях, являющихся следствием длительного диспергирования.

Ключевые слова: оксид цинка, размол, аттритор, ИК фурье-спектроскопия, КР-спектроскопия.

DOI: $10.21883 / J T F .2019 .09 .48067 .437-18$

\section{Введение}

Сегодня ультрадисперсные порошки широкозонных полупроводниковых металлооксидов, таких как $\mathrm{ZnO}$, $\mathrm{TiO}_{2}, \mathrm{In}_{2} \mathrm{O}_{3}, \mathrm{CeO}_{2}$ и др., находят применение в различных областях науки и техники [1,2]. Ярким представителем данной группы материалов является оксид цинка, высокая востребованность которого обусловлена уникальной комбинаций электрофизических, оптических и химических свойств, а также доступностью сырья и возможностью создания энергоэффективного и экологически приемлемого производства $[3,4]$. Он используется для создания нанолазеров, пьезоэлектрических наногенераторов, солнечных элементов, газовых сенсоров и других элементов и устройств наноэлектроники $[5,6]$.

При этом значительный интерес представляет использование оксида цинка в фотокаталитических приложениях. В прошлом десятилетии наибольшее внимание среди полупроводниковых фотокатализаторов уделялось диоксиду титана, который благодаря низкой себестоимости и хорошей химической стабильности широкомасштабно изучался для целей фотодеградации органических соединений, например, насыщенных и ароматических углеводородов [7,8], пестицидов [9] и т. д. По сравнению с оксидом титана оксид цинка является менее изученным материалом, однако в ряде работ [10-12] было показано, что $\mathrm{ZnO}$, в том числе полученный с помощью диспергирования коммерческого порошка, демонстрирует более высокую эффективность и более широкий спектр поглощения солнечного излучения. В целом, несмотря на достаточную изученность процессов, протекающих при размоле порошков $\mathrm{ZnO}$ [13], их структурная эволюция исследована и проанализирована недостаточно, что определяет цель настоящей работы.

\section{Методика эксперимента}

В рамках механического высокоэнергетического размола, синтез ультрадисперсных порошков оксида цинка осуществлялся следующим образом (рис. 1). В стакан аттритора (Union Process HD/01) помещался вал с лопастями цилиндрической формы из $\mathrm{ZrO}_{2}$ и засыпались мелющие тела, в качестве которых использовались шарики оксида циркония диаметром $3 \mathrm{~mm}$. После включения аттритора на скорости перемешивания 50-100 rot $/ \mathrm{min}$ в стакан засыпался коммерческий порошок $\mathrm{ZnO}$ (чда „Вектон“) до его равномерного распределения по всему 


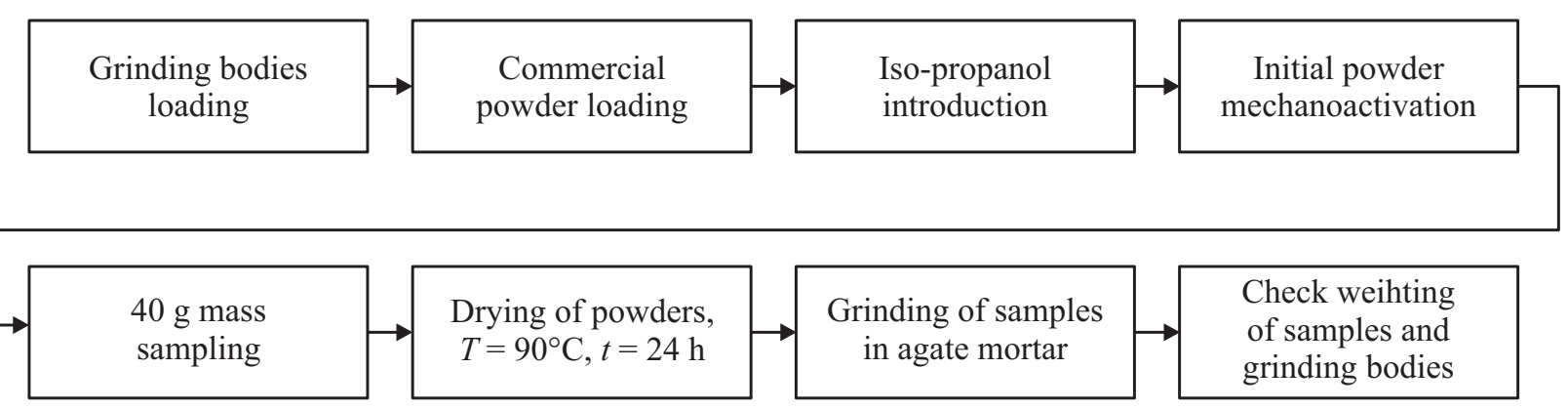

Рис. 1. Основные этапы получения ультрадисперсных порошков оксида цинка.

объему и изопропиловый спирт (чда) для проведения мокрого размола [14].

После закрытия крышки аттритора скорость вращения вала постепенно увеличивалась до 400-500 rot $/ \mathrm{min}$. Измельчение проводилось во временном интервале $30 \mathrm{~min}-5 \mathrm{~h}$. Отбор проб осуществлялся через каждые $30 \mathrm{~min}$, при этом скорость вращения вала уменьшалась до $100 \mathrm{rot} / \mathrm{min}$. С помощью дозатора жидкие пробы помещались в бюксы. Сушка порошков проводилась в лабораторном сушильном шкафу при температуре $70^{\circ} \mathrm{C}$ в течение $24 \mathrm{~h}$. Затем образцы остужались до комнатной температуры и перетирались в агатовой ступке для устранения агломератов, возникших во время сушки.

Определение удельной площади поверхности ультрадисперсных порошков $\mathrm{ZnO}$ и среднего размера зерна проводилось при помощи метода тепловой десорбции азота на приборе „Сорби MS“ (Новосибирск, Россия).

ИК-спектры пропускания изготовленных порошков оксида цинка получены на ИК-фурье-спектрометре ФСМ 1201 (ООО „Инфраспек“, Россия). Образцы готовили в виде прессованных с бромидом калия таблеток при массовом соотношении $\mathrm{ZnO}: \mathrm{KBr}$ 1:30.

Микроскопические изображения ультрадисперсных порошков $\mathrm{ZnO}$ были получены на сканирующем электронном микроскопе Hitachi S3400N (Япония) в режиме вторичных электронов. Обработка и анализ изображений проводились с использованием графического редактора ImageJ. Каждый отдельный кристаллит выделялся замкнутым контурным изображением, после чего всем точкам внутри контура присваивался черный цвет, а точкам вне контура - белый. В результате такой обработки формировались черно-белые изображения, на которых черные области соответствовали частицам $\mathrm{ZnO}$, после чего оценивалась их площадь и геометрические размеры.

Спектры комбинационного рассеяния (КР) образцов регистрировались на спектрометре LabRamHR800 в геометрии обратного рассеяния при комнатной температуре. Источником возбуждения являлась вторая гармоника $\mathrm{Nd}$ :YAG-лазера $(\lambda=532 \mathrm{~nm})$, лазерный луч фокусировался на поверхности порошка в пятно диаметром $1-2 \mu \mathrm{m}$.

\section{Результаты и их обсуждение}

Экспериментальные данные, полученные с помощью сканирующей электронной микроскопии, однозначным образом свидетельствуют о структурной эволюции порошков оксида цинка, подвергнутых механическому высокоэнергетическому размолу (рис. 2).

По результатам проведенного анализа микроскопических изображений порошков $\mathrm{ZnO}$ можно сделать следующие основные выводы. Во-первых, исходные порошки коммерческого оксида цинка преимущественно состоят из вытянутых гексагональных призм с основанием размером 150-250 nm, при этом наблюдается значительная дисперсия, следствием которой является наличие крупных элементов, превышающих по одному из линейных размеров $500 \mathrm{~nm}$ (рис. 2,a). Во-вторых, диспергирование в течение 30 и более минут приводит к изменению среднего размера кристаллитов, который по близкой к линейной зависимости уменьшается до 100-150 nm (рис. 2,d). В-третьих, существенно уменьшается разброс по размерам, что иллюстрирует представленная на рис. 3 диаграмма.

В целом экспериментальные данные, полученные с помощью сканирующей электронной микроскопии, находятся в согласии с результатами измерений в рамках метода тепловой десорбции азота. В частности, для коммерческого порошка оксида цинка получена величина размера частиц $200 \mathrm{~nm}$, а для образцов, измельченных в течение 1,3 и 5 h она составляет 180,140 и $110 \mathrm{~nm}$ соответственно. Измерения полной удельной поверхности по методу Брунауэра-Эметта-Теллера демонстрируют ее практически двукратное увеличение с $5.4 \mathrm{~m}^{2} / \mathrm{gm}$ (для исходного порошка) до $6.1,7.6$ и $10.0 \mathrm{~m}^{2} / \mathrm{gm}$ для образцов, диспергированных в течение 1,3 и 5 h соответственно.

Использование инфракрасной фурье-спектроскопии для анализа структурной эволюции порошков оксида цинка позволяет получить важную информацию не только о качественном составе порошков $\mathrm{ZnO}$, но и о состоянии приповерхностных областей кристаллитов (рис. 4).

Характерной особенностью анализируемых ИК-спектров является наличие существенного числа мод поглощения, отвечающих не только ультрадисперсному 

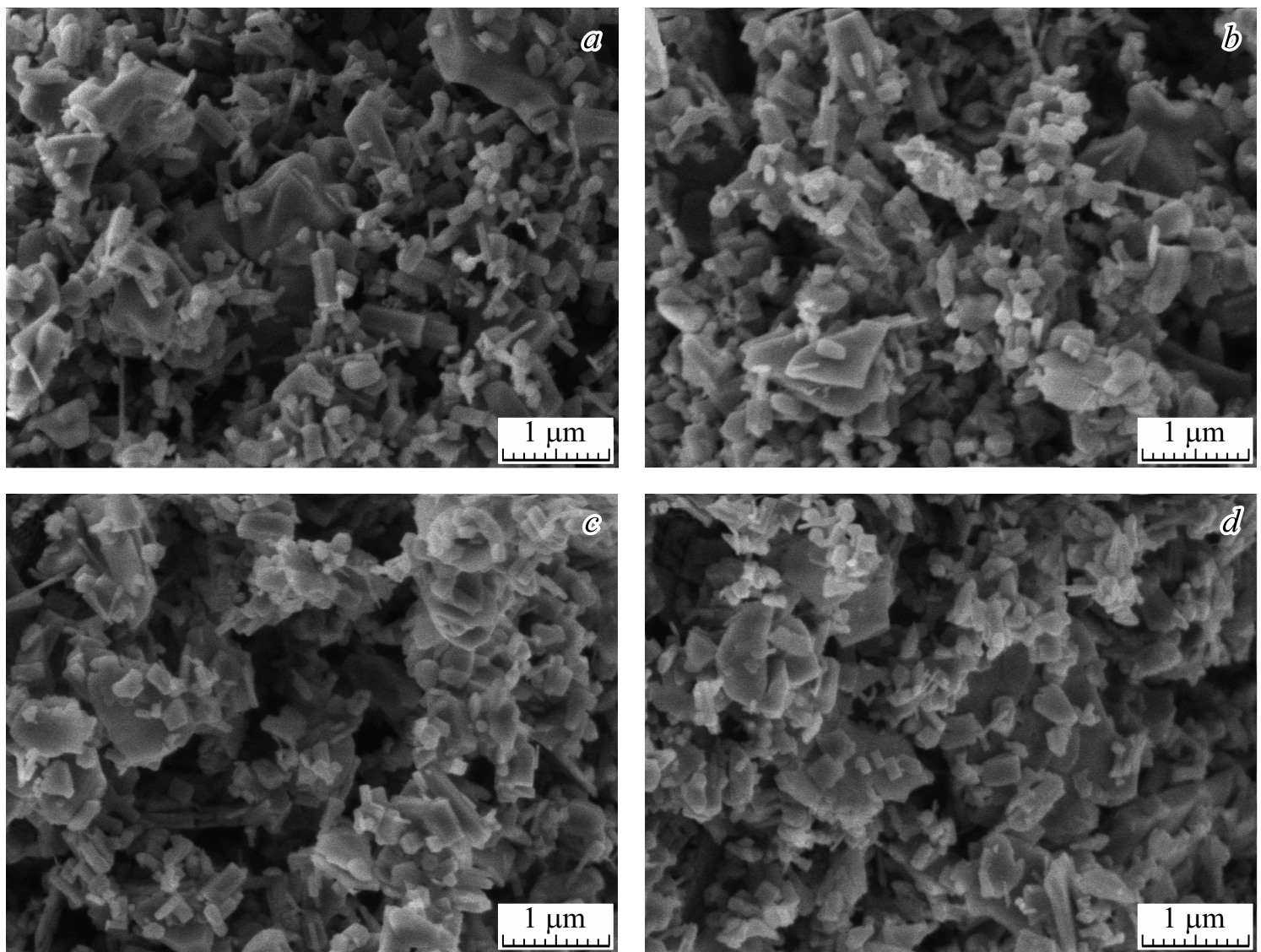

Рис. 2. Микроскопические изображения порошков $\mathrm{ZnO}: a-$ исходный коммерческий порошок, $b-1 \mathrm{~h}$ размола, $c-2 \mathrm{~h}$ размола, $d-3 \mathrm{~h}$ размола.

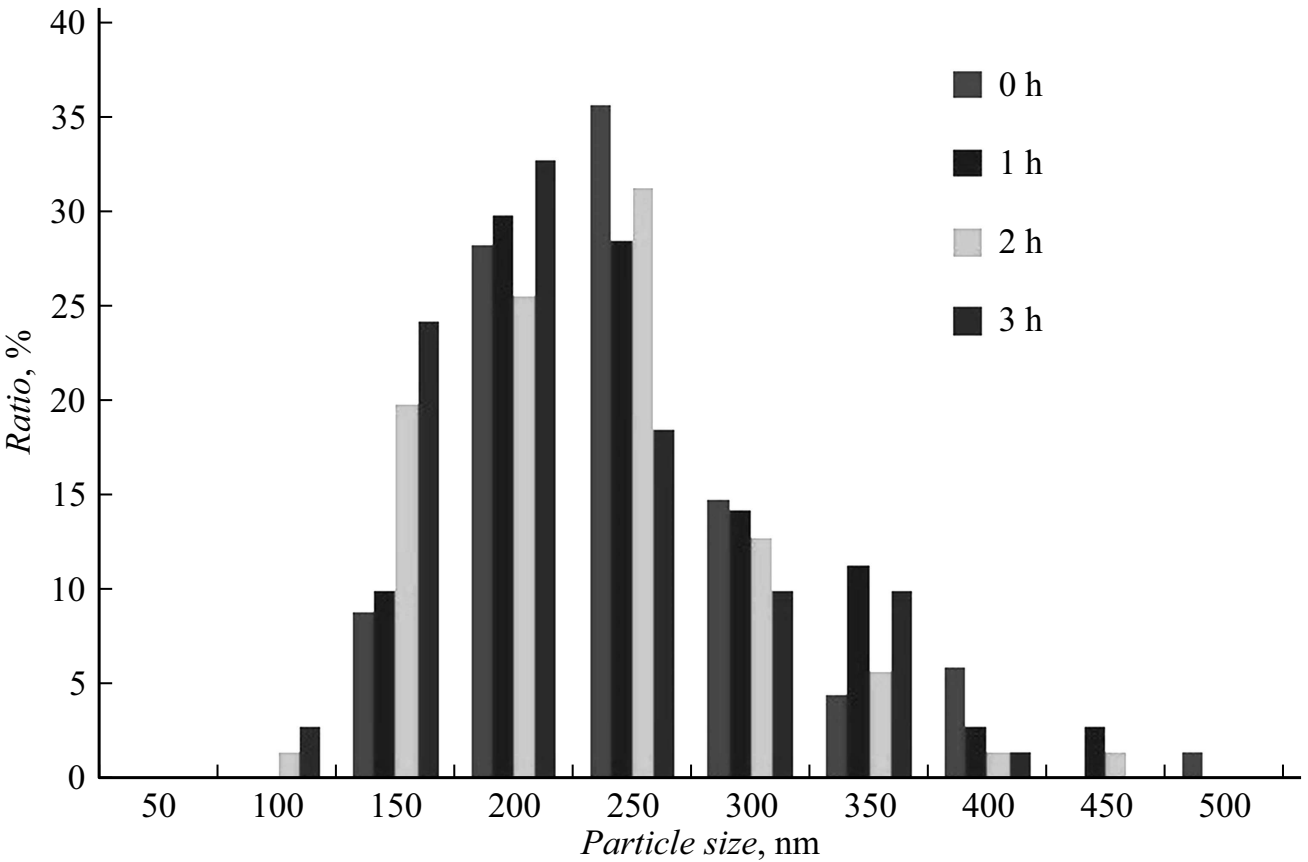

Рис. 3. Распределение размера частиц оксида цинка, полученных методом механического высокоэнергетического размола. 


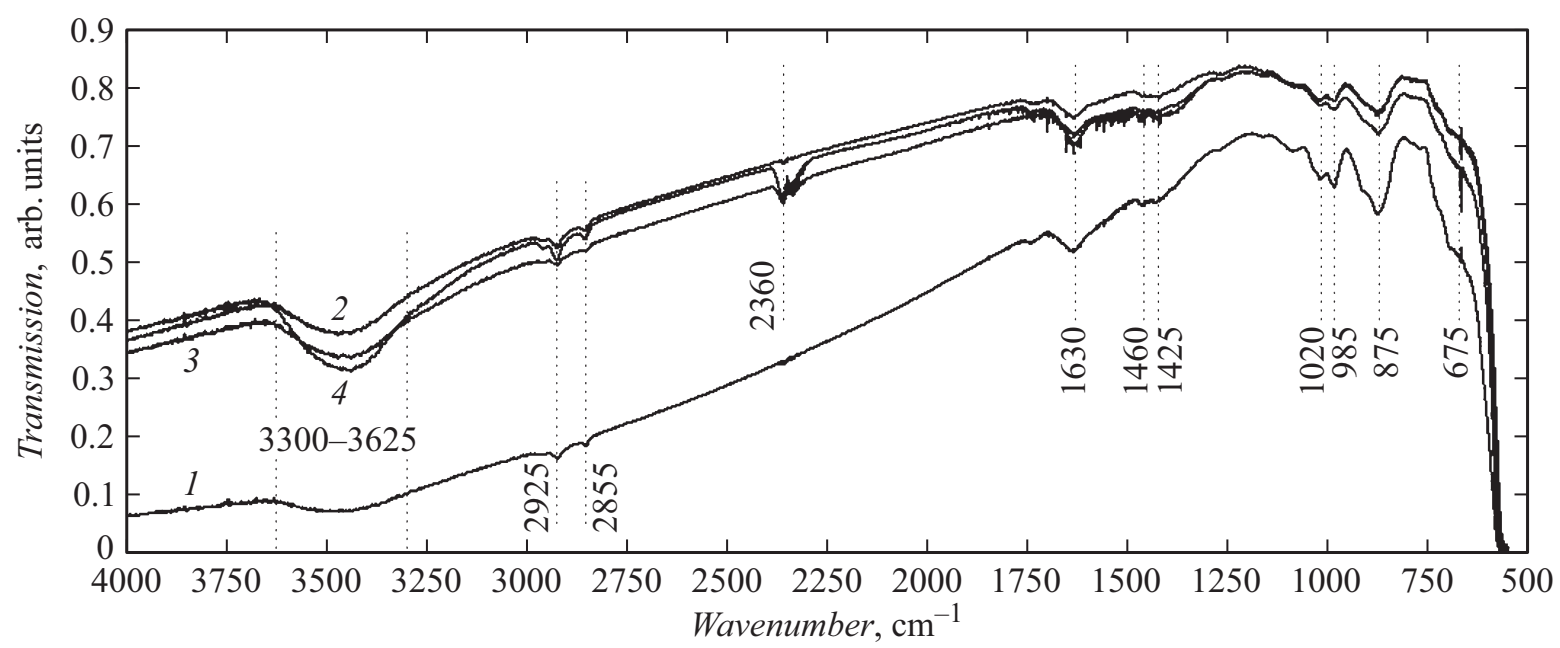

Рис. 4. ИК-спектры пропускания порошков $\mathrm{ZnO}$ при различном времени механического высокоэнергетического размола: 1 исходный образец, $2-1 \mathrm{~h}$ размола, $3-3 \mathrm{~h}$ размола, $4-5 \mathrm{~h}$ размола.

порошку $\mathrm{ZnO}$, но и органическим и неорганическим соединениям, адсорбированным на поверхности частиц порошка [15]. Так, широкая полоса поглощения $3300-3625 \mathrm{~cm}^{-1}$, характеризующая валентные колебания ОН-групп, однозначно указывает на активное взаимодействие оксида цинка с атмосферной влагой. Малая интенсивность данной полосы у исходного образца и ее существенное увеличение у образцов, измельченных в течение 1,3 и $5 \mathrm{~h}$, связаны со структурной эволюцией $\mathrm{ZnO}$, которая сопровождается не только уменьшением среднего размера частиц оксида цинка, но и изменением концентрации центров Льюиса и Бренстеда на их поверхности [16]. Бренстедовские основания и кислоты образуются в результате адсорбции воды или ее фрагментов на соответствующих апротонных центрах. Для оксида цинка они представлены гидроксильными группами трех типов $-\mathrm{OH}^{-}, \mathrm{OH}^{\bullet}, \mathrm{OH}^{+}$различной зарядности. Рост интенсивности пика поглощения при $2360 \mathrm{~cm}^{-1}$, отвечающего валентным колебаниям связей $\mathrm{C}=\mathrm{O}$ в молекуле $\mathrm{CO}_{2}$, для обработанных образцов также отвечает вышеуказанным процессам.

Характеристическими модами, соответствующими непосредственно $\mathrm{ZnO}$, являются мода при $500 \mathrm{~cm}^{-1}$ и узкая полоса поглощения при $675 \mathrm{~cm}^{-1}$, наблюдаемые при деформационных решеточных колебаниях связей $\mathrm{Zn}=\mathrm{O}[17,18]$. Сильное смещение низкоэнергетической моды при $500 \mathrm{~cm}^{-1}$ (по сравнению с объемным кристаллом, для которого характерно ее положение около $450 \mathrm{~cm}^{-1}$ ) может быть объяснено микродеформациями кристаллической решетки. Присутствие в ИК-спектрах полос и пиков поглощения при 2925, 2855, 1465 , $1425 \mathrm{~cm}^{-1}$ отвечает остаткам изопропилового спирта (частично дегидрированного до ацетона), применяемого в процессе высокоэнергетического механического размола с учетом последующей мягкой сушки, в процессе которой полного удаления спирта не происходит. Так, моды 2925 и $2855 \mathrm{~cm}^{-1}$ однозначно соответствуют валентным симметричным и ассиметричным колебаниям $\mathrm{CH}_{2}$-групп, а моды при 1465 и $1425 \mathrm{~cm}^{-1}$ характеризуют деформационные колебания $R-\mathrm{O}-\mathrm{H}$.

В ИК-спектрах исследуемых ультрадисперсных порошков $\mathrm{ZnO}$ также присутствуют линии поглощения при 875, 985, 1020 и $1630 \mathrm{~cm}^{-1}$. Первая из них $\left(875 \mathrm{~cm}^{-1}\right)$ отвечает колебанию карбонатной моды $\mathrm{O}-\mathrm{C}-\mathrm{O}$, которая обычно наблюдается при спектроскопических измерениях вне вакуума [19]. Мода $1630 \mathrm{~cm}^{-1}$ соответствует деформационным колебаниям $\mathrm{H}-\mathrm{O}-\mathrm{H}$ и отвечает наличию в исследуемых образцах воды в несвязанном виде, которая не удаляется полностью в процессе сушки. Моды при 985 и $1020 \mathrm{~cm}^{-1}$ достоверно не идентифицируется, однако, наиболее вероятно, соответствуют колебаниями связей $\mathrm{Zn}-\mathrm{O}$ на поверхности, где катион $\mathrm{Zn}^{2+}$ является координационно ненасыщенным, а также многофононным колебаниям решетки $\mathrm{ZnO}[20]$.Это согласуется с идеей множественных разрывов связей в приповерхностных областях, являющихся следствием длительного диспергирования.

Экспериментальные данные, полученные с помощью спектроскопии комбинационного рассеяния (КР), дополняют и подтверждают результаты инфракрасной фурье-спектроскопии (рис. 5). В частности известно $[21,22]$, что вюрцитная структура $\mathrm{ZnO}$ принадлежит к пространственной группе $C_{6 v}^{4}$ и имеет примитивную ячейку, содержащую $n=4$ атома (2 молекулярные единицы $\mathrm{Zn}-\mathrm{O})$. Такого рода структуре отвечает $3 n=12$ фононам, 3 из которых соответствуют акустическим модам $(1 x L A, 2 x T A)$ и $3 n-3=9$ оптическим модам $(3 x L O, 6 x T O)$. Теория групп предсказывает, что в Г-точке зоны Бриллюэна оптические фононы имеют неприводимое представление: $\Gamma=A_{1}+2 B_{1}+E_{1}+2 E_{2}$. Моды $A_{1}$ и $E_{1}$ являются полярными и разделены на поперечные оптические $\left(A_{1} T O\right.$ и $\left.E_{1} T O\right)$ и продоль- 


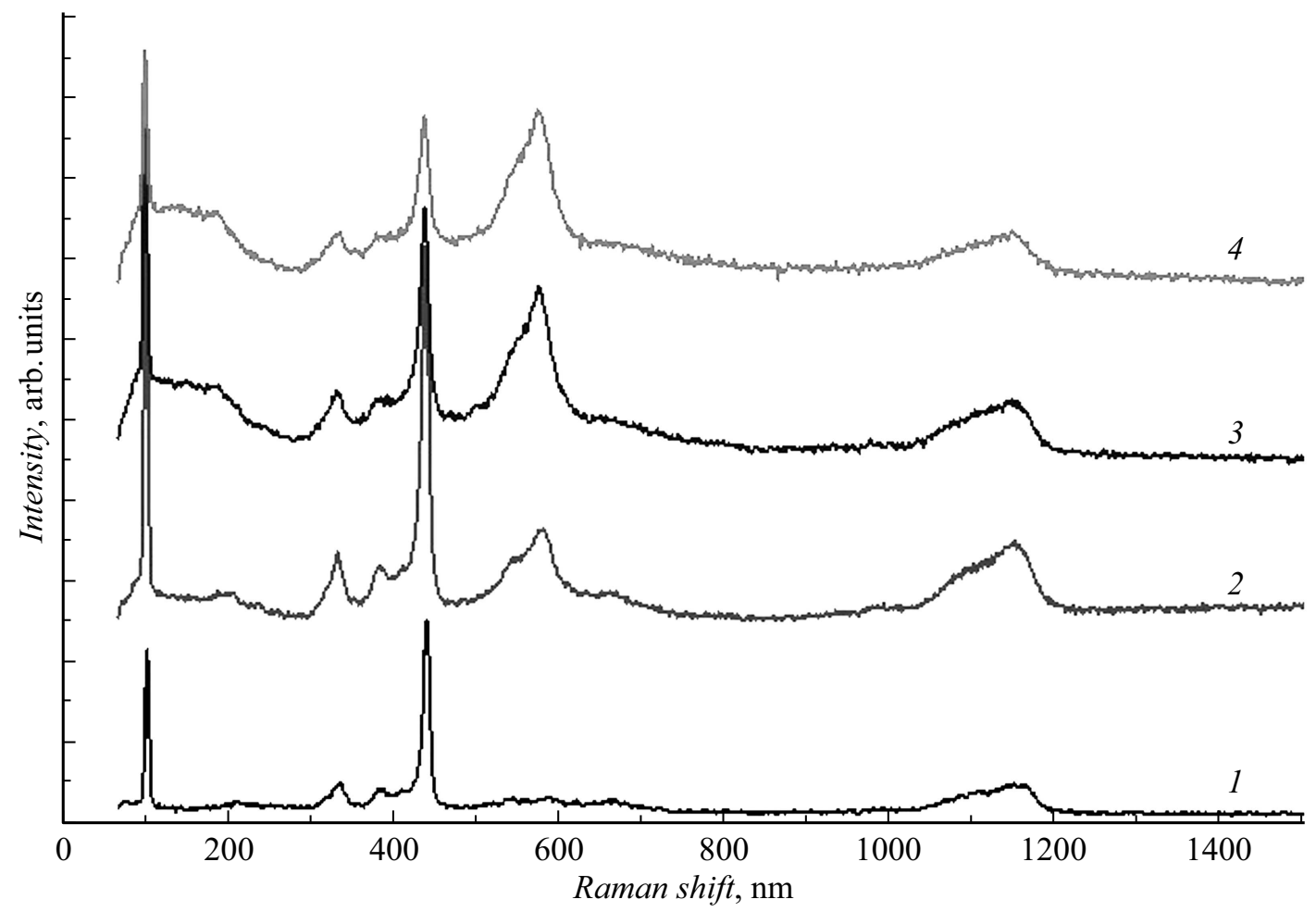

Рис. 5. КР-спектры порошков $\mathrm{ZnO}$ при различном времени механического высокоэнергетического размола: 1 - исходный образец, $2-1 \mathrm{~h}$ размола, $3-3 \mathrm{~h}$ размола, $4-5 \mathrm{~h}$ размола.

ные оптические $\left(A_{1} L O\right.$ и $\left.E_{1} L O\right)$ компоненты. $E_{2}$ мода включает низкочастотную и высокочастотную составляющую $\left(E_{2}^{\text {low }}\right.$ и $\left.E_{2}^{\text {high }}\right)$, что отвечает колебаниями подрешеток $\mathrm{Zn}$ и $\mathrm{O}$ соответственно. Моды $B_{1}$ являются „молчащими“ и не активны при комбинационном рассеянии света. В целом на КР-спектрах порошков оксида цинка, полученных при различном времени диспергирования, можно выделить следующие моды: 1) с частотой $\sim 100 \mathrm{~cm}^{-1}$; 2) моду при $\sim 340 \mathrm{~cm}^{-1}$, которую относят к разностному фонону $E_{2}^{\text {high }}-E_{2}^{\text {low }}$; 3$)$ при $\sim 435 \mathrm{~cm}^{-1}$; 4) $E_{1}(L O)$ при $\sim 580 \mathrm{~cm}^{-1}$; 5) широкую полосу между 1060 и $1190 \mathrm{~cm}^{-1}$, которую можно отнести к комбинации мод $A_{1}$ и $E_{2}$.

Основное спектральное изменение, наблюдаемое в КР-спектрах исследуемых образцов, заключается в монотонном увеличении интенсивности $E_{1}(L O)$ моды $\left(580 \mathrm{~cm}^{-1}\right)$ и появлении плеча в области $100-200 \mathrm{~cm}^{-1}$. Данное явление может быть объяснено микродеформациями кристаллической решетки, а также присутствием в материале примесей или точечных дефектов. Данный результат, по всей видимости, отвечает тому факту, что с ростом времени измельчения будет возрастать концентрация дефектов в оксиде цинка, а также наблюдаться множественные разрывы связей в приповерхностных областях, что подтверждается результатами исследования спектров распределения центров адсорбции (РЦА) [16].

\section{Заключение}

Таким образом, с использованием современных аналитических методов исследований показано, что механический высокоэнергетический размол коммерческих порошков оксида цинка позволяет получать однородные (с малой дисперсией по размеру кристаллитов) образцы, обладающие высокой удельной площадью поверхности $\left(10 \mathrm{~m}^{2} / \mathrm{gm}\right.$ при размоле $\left.5 \mathrm{~h}\right)$. Структурная эволюция порошков $\mathrm{ZnO}$ проявляется в реконструкции поверхности, которая сопровождается изменением числа и соотношения адсорбционных центров, а также образованием множества дефектов, в том числе за счет разрыва связей в приповерхностных областях. Полученные результаты могут представлять интерес при создании на основе такого рода порошков высокоэффективных фотокатализаторов, активных, в том числе в видимом диапазоне оптического излучения.

\section{Финансирование работы}

Работа выполнена при финансовой поддержке Министерства образования и науки РФ (проект 16.897.2017/ПЧ), а также Стипендий и Гранта президента РФ (СП-84.2018.1, СП-3800.2018.1, МК1882.2018.8). 


\section{Конфликт интересов}

Авторы заявляют, что у них нет конфликта интересов.

\section{Список литературы}

[1] Wang N., Li X., Wang Y., Hou Y., Zou X., Chen G. // Mater. Lett. 2008. Vol. 62. N 21-22. P. 3691-3693. DOI: 10.1016/j.matlet.2008.04.052

[2] Özgür U., Alivov Ya.I., Liu C., Teke A., Reshchikov M.A., Doğan S., Avrutin V., Cho S.J., Morko H. // J. Appl. Phys. 2005. Vol. 98. N 4. P. 1-103. DOI: 10.1063/1.1992666

[3] Chin Boon Ong, Law Yong Ng, Abdul Wahab Mohammad // Renewable and Sustainable Energy Review. 2018. Vol. 81. P. 536-551. DOI: 10.1016/j.rser.2017.08.020

[4] Dimitrov D.T., Nikolaev N.K., Papazova K.I., Krasteva L.K., Bojinova A.S., Peshkova T.V., Kaneva N.V., Pronin I.A., Averin I.A., Yakushova N.D., Karmanov A.A., Georgieva A.T., Moshnikov V.A. // Appl. Surf. Sci. 2017. Vol. 392. P. 95-108. DOI: 10.1016/j.apsusc.2016.08.049

[5] Huang M., Mao S., Feick H., Yan H., Wu Y., Kind H., Weber E., Russo R., Yang P. // Science. 2001. Vol. 292. P. 1897-1899. DOI: $10.1126 /$ science. 1060367

[6] Wang Z., Song J. // Science. 2006. Vol. 312. P. 242-246. DOI: $10.1126 /$ science. 1124005

[7] Klare M., Scheen J., Vogelsang K., Jacobs $H$., Broekaert J.A. // Chemosphere. 2000. Vol. 41. P. 353-362. DOI: $10.1016 / \mathrm{S} 0045-6535(99) 00447-6$

[8] Cermenati L., Dondi D., Fagnoni M., Albini A. // Tetrahedron. 2003. Vol. 59. P. 6409-6414.

DOI: 10.1016/S0040-4020(03)01092-5

[9] Autin O., Hart J., Jarvis P., MacAdam J., Parsons S.A., Jefferson B. // Water Res. 2013. Vol. 47. P. 2041-2049. DOI: 10.1016/j.watres.2013.01.022

[10] Qiu R., Zhang D., Mo Y., Song L., Brewer E., Huang X., Xiong Y. // J. Hazard Mater. 2008. Vol. 156. P. 80-85. DOI: 10.1016/j.jhazmat.2007.11.114

[11] Bhatia S., Verma N. // Mater. Res. Bulletin. 2017. Vol. 92. P. 468-476. DOI: 10.1016/j.materresbull.2017.08.019

[12] Пронин И.А., Канева Н.В., Божсинова А.С., Аверин И.А., Папазова К.И., Димитров Д.Ц., Мочников В.А. // Кинетика и катализ. 2014. Т. 55. № 2. С. 176. [Pronin I.A., Kaneva N.V., Bozhinova A.S. Averin I.A., Papazova K.I., Dimitrov D.Ts., Moshnikov V.A. DOI: $10.1134 / \mathrm{S} 0023158414020074]$

[13] Chen D., Ai S., Liang Z., Wei F. // Ceram. Int. 2016. Vol. 42. N 2. P. 3692-3696. DOI: $10.1016 /$ j.ceramint.2015.10.123

[14] Yakushova N.D., Pronin I.A., Averin I.A., Vishnevskaya G.V., Sychov M.M., Levitsky V.S., Karmanov A.A., Moshnikov V.A. // J. Phys.: Conf. Series. 2017. Vol. 872. P. 012032. DOI: $10.1088 / 1742-6596 / 872 / 1 / 012032$

[15] Аверин И.А., Карманов А.А., Мочников В.А., Пронин И.А., Игошина С.Е., Сигаев А.П., Теруков Е.И. // ФТТ. 2015. T. 57. Вып. 12. С. 2304-2312. [Averin I.A., Karmanov A.A., Moshnikov V.A., Pronin I.A., Igoshina S.E., Sigaev A.P., Terukov E.I. // Phys. Solid State. 2015. Vol. 57. N 12. P. 23732381. DOI: $10.1134 / \mathrm{S} 1063783415120069]$

[16] Пронин И.А., Якушова Н.Д., Сычев М.М., Комолов А.С., Мякин С.В., Карманов А.А., Аверин И.А., Мошников В.A. // ФХС. 2018. Т. 44. № 5. C. 560-572. [Pronin I.A., Yakushova N.D., Sychev M.M., Komolov A.S., Myakin S.V., Karmanov A.A., Averin I.A., Moshnikov V.A. // Glass Phys. Chem. 2018. Vol. 44. N 5. P. 464-473.

DOI: $10.1134 / \mathrm{S} 1087659618050140]$
[17] Sharma D., Jha R. // Ceram. International. 2017. Vol. 43. N 11. P. 8488-8496. DOI: $10.1016 /$ j.jallcom.2016.12.227

[18] Kumar S., Mukherjee S., Singh R.Kr., Chatterjee S., Ghosh A.K. // J. Appl. Phys. 2011. Vol. 110. P. 103508. DOI: $10.1063 / 1.3658221$

[19] Mohamed W.S., Abu-Dief A.M. // J. Phys. Chem. Sol. 2018. Vol. 116. P. 375-385. DOI: 10.1016/j.jpcs.2018.02.008

[20] Davydov A. Molecular spectroscopy of oxide catalyst surfaces. Chichester: John Wiley \& Sons Ltd., 2003. 641 p.

[21] Cusco R., Alarcon-Llado E., Ibanez J., Artus L., Jimenez J., Wang B., Callahan M.J. // Phys. Rev. B. 2007. Vol. 75. P. 165202. DOI: 10.1103/PhysRevB.75.165202

[22] Zhang R., Yin P.-G., Wang N., Guo L. // Solid State Sci. 2009. Vol. 11. P. 865-869.

DOI: $10.1016 /$ j.solidstatesciences.2008.10.016 